\title{
Emergence and development of H7N9 influenza viruses in China
}

Huachen Zhu*, Tommy Tsan-Yuk Lam, David Keith Smith, Yi Guan

${ }^{1}$ Joint Influenza Research Centre (SUMC/HKU), Shantou University Medical

College, Shantou 515041, China.

${ }^{2}$ State Key Laboratory of Emerging Infectious Diseases (HKU-Shenzhen Branch),

Shenzhen Third People's Hospital, Shenzhen 518112, China.

${ }^{3}$ Centre of Influenza Research, School of Public Health, The University of Hong

Kong, Hong Kong, China

*Corresponding author. Email: zhuhch@ hku.hk 


\section{Abstract}

The occurrence of human infections with avian H7N9 viruses since 2013 demonstrates the continuing pandemic threat posed by the current influenza ecosystem in China. Influenza surveillance and phylogenetic analyses showed that these viruses were generated by multiple interspecies transmissions and reassortments among the viruses resident in domestic ducks and the H9N2 viruses enzootic in chickens. A large population of domestic ducks hosting diverse influenza viruses provided the precondition for these events to occur, while acquiring internal genes from enzootic H9N2 influenza virus in chickens promoted the spread of these viruses. Human infections effectively act as sentinels, reflecting the intensity of the activity of these viruses in poultry. 


\section{Highlights}

- H7N9 virus was generated through sequential reassortments in ducks and chickens.

- This virus originated from eastern China and has spread to over 20 provinces.

- Regionally distinct lineages have been established with different genotypes.

- Viruses present at live poultry markets fueled the recurrence of human infections.

- Chickens served as the source of human infections in each outbreak wave. 


\section{Main text}

\section{Introduction}

Transmissions of influenza viruses from wild aquatic birds to poultry have been seen in many different countries almost every year and may lead to sporadic human infections [1]. However, it is rare that an avian influenza virus not yet recognized in poultry is first identified as the causative agent of human infectious diseases. The two examples that stand out are the 1997 Hong Kong H5N1 and the 2013 H7N9 avian influenza outbreaks [2,3].

Human infections with the H7N9 influenza virus total 679 cases from the three outbreak waves (waves I to III) in China (Figs. 1-2), with a fatality rate of about $40 \%$ (Food and Agriculture Organization of the United Nations; URL: http://www.fao.org/ag/againfo/programmes/en/empres/H7N9/wave_3/Situation_u pdate_2015_09_29.html). The incidence of human infections was affected by disease control measures, seasonality factors and reflected the activity of the virus in poultry [4-10]. Although the increasing numbers of human infections with the H7N9 influenza viruses have raised concerns of a pandemic threat, the implementation of measures to control the spread of this and related viruses has remained controversial.

In this review we summarize the emergence and epidemiology of human infections with the H7N9 virus, its origin and genesis in birds and its subsequent evolution, dissemination and development. We follow this with a discussion of the emergence of related viruses such as the $\mathrm{H} 10 \mathrm{~N} 8$ virus and consider the ecological factors in China that favour the emergence of influenza viruses and look at control measures that can be applied in this context. 


\section{Emergence and epidemiology of human infections of the H7N9 influenza virus}

Even though it was first recognized in Shanghai [3], the 2013 H7N9 avian influenza virus likely emerged from Zhejiang or Jiangsu in the Yangzi River Delta region adjacent to Shanghai. Zhejiang reported the largest number of human infections in wave I (Fig. 1), which might favour it being the source of the H7N9 influenza virus, and reported the index cases of waves II, III and IV [9-12] (World Health Organization; URL: http://www.who.int/entity/influenza/human_animal_interface/avian_influenza/arc hive/en/index.html). Phylogenetic analyses revealed that the H7N9 viruses from the Yangzi River Delta region had the highest diversity relative to those from other regions and were often closer to the roots of the $\mathrm{H} 7$ and N9 phylogenies than viruses from other regions [13]. H7N9 viruses were introduced into Guangdong in April 2013 and then spread rapidly in the Pearl River Delta region in poultry [13-16]. During waves II and III, Guangdong reported the largest number of cases of human infections (Fig. 1).

The direction of dissemination of the wave I virus has been from the eastern provinces (Zhejiang and Jiangsu) to their nearby regions, such as Anhui, Henan, Beijing, Shandong, Fujian, Jiangxi, Hunan and Hubei (Fig. 1). In wave II and III, the viruses disseminated to affect over 20 provinces in eastern, southern and central China and Xinjiang (Fig. 1). Imported cases have also been reported in Taiwan, Macao, Hong Kong, Canada and Malaysia (Fig. 1).

The emergence of human infections with avian influenza viruses is usually associated with the activity of viruses in poultry, including virus prevalence, poultry type and density, mode of exposure and transmission pathway. Although family or hospital clusters of human cases were recognized, it is believed that the H7N9 avian viruses cannot efficiently transmit from human-to-human [4,17-22]. 
At least two thirds of the human infection cases with the H7N9 viruses had a history of exposure to chickens before disease onset, mostly at live-poultry markets $[4-6,9,23]$. It was also noticed that after the human infections were confirmed, local authorities could often isolate or detect the H7N9 influenza viruses at live-poultry markets, mainly from chickens or environmental samples [10, 23-25]. Closure of the live-poultry markets in different cities has effectively stopped the disease outbreak afterwards [7,8,24-28]. Unfortunately, due to the asymptomatic infections [29-31] and the lack of timely and effective surveillance in poultry, infections in humans actually act as sentinels of the presence of the virus in birds.

\section{Origin and genesis of the H7N9 influenza virus}

After the sequences of the H7N9 avian influenza viruses became publicly accessible, initial analyses concluded that this virus was generated by reassortment between viruses from wild bird $\mathrm{H} 7$ and N9 viruses (surface genes) and poultry $\mathrm{H} 9 \mathrm{~N} 2$ viruses (internal genes) [23,32,33].

Systematic analyses of long-term influenza surveillance showed that the $\mathrm{H} 7$ subtype of influenza viruses had been transmitted on multiple occasions from migratory birds to domestic ducks during the last twelve years and maintained in domestic ducks [34] (Fig. 3). N9 viruses had similar introductions and evolutionary pathways [34]. Thus, domestic ducks likely played key roles by maintaining wild bird viruses, increasing their prevalence, facilitating the formation of precursor viruses and transmitting viruses to chickens (Fig. 4).

After introduction to chickens, H7 and N9 viruses reassorted with the enzootic H9N2 viruses, adopting their internal gene complex to form the H7N9 virus that emerged in 2013 [32-36] (Fig. 3). Incorporation of the H9N2 internal gene 
complex likely increased the ability of viruses with aquatic bird origin surface genes to replicate in chickens, thereby facilitating their spread in a new host.

The detection of H7N7 duck influenza viruses and the genetically related H7N7 chicken viruses, which had internal genes from enzootic H9N2 viruses (Fig. 3), at the same live-poultry market in Zhejiang in April 2013 [34], suggest that this type of interspecies transmission and subsequent reassortment occurs more frequently than previously recognized.

\section{Evolution, dissemination and development of the H7N9 influenza virus}

Phylogenetic analysis of the HA and NA genes showed that the early H7N9 viruses formed a highly polytomous clade [13,34] (Fig. 2), suggestive of dispersal of near identical viruses from a common source. However, analyses of their internal genes revealed multiple genotypes, with internal genes from different H9N2 sub-lineages [13,33-36] (Fig. 3). This genotypic diversity may be caused by sequential reassortments after the viruses were introduced to different regions or by several distinct ressortment events occurring approximately simultaneously when the viruses were initially generated.

Early H7N9 viruses, with highly similar surface genes, were detected in six provinces or municipalities (i.e., Shanghai, Zhejiang, Jiangsu, Anhui, Shandong, Hunan and Guangdong) within a very short period of time (less than 1.5 months) [13,33-36], and in each wave human and chicken viruses were always clustered together in the phylogenetic trees (Figs. 2-3). This suggested that the H7N9 viruses were transmitted rapidly in the field, likely by transportation of poultry as part of the marketing system. Spatio-temporal aggregation of chicken viruses and human cases was also observed, supporting a market-based dissemination of the H7N9 viruses [37,38]. 
The outbreaks of waves II and III started in the early autumn of 2013 and 2014 respectively, with the H7N9 influenza viruses developing into different clades and being disseminated over a wider region of China than in wave I [9-13] (Fig. 2). Phylogenetic analyses of H7N9 surface genes showed three distinct clades, A, B and $\mathrm{C}$, that were responsible for all reported human infections in waves II and III where sequences were available [13] (Fig. 2). Viruses in clade A were descendants of those maintained in Eastern China, and were occasionally transmitted to other regions such as Guangdong and Jiangxi [13]. Clade B was formed by viruses exclusively from Guangdong, and was especially localized in the Pearl River Delta region, indicating that these viruses were maintained and diverged in this region, which imports but rarely exports chickens [13]. The root of clade B could be traced to the earliest strains detected in Guangdong in April and May 2013 [13-16]. Clade C was largely isolated from Jiangxi during the Wave II, but also found in human cases imported to Taiwan from Jiangsu [13] and from Xinjiang, the far northeast province (Fig. 2).

Whole genome analysis of waves II and III H7N9 viruses revealed their shift from the original major genotype of wave I to a number of genotypes that predominated in different regions [13]. No viruses of the original major genotype were detected in the subsequent waves [13]. Many of the new genotypic variants acquired internal genes from local H9N2 viruses, resulting in more than 30 genotypes in wave II $[13,33,35,36]$. Two H7N6 reassortant variants, with N6 genes from H5N6 viruses and all other segments from H7N9 viruses, were detected in Wave II [13]. Wave III viruses emerged from each of the wave II clades (A, B and C), indicating the continuing presence and evolution of the viruses (Fig. 2).

\section{The emergence and development of the H10N8 influenza virus}

Coincident with the second outbreak wave of H7N9 in the winter of 2013-2014, an avian H10N8 influenza virus emerged and caused three human infections in 
Nanchang, Jiangxi province, a region adjacent to Poyang Lake, a major aggregation site for overwinter migratory birds and the biggest freshwater body in eastern Asia. The first case was reported in November 2013 and the second and third in January and February 2014, respectively [39,40].

Surveillance and phylogenetic analyses revealed a similar genesis pathway to that of the H7N9 influenza virus [40-43]. The H10 subtype of avian influenza viruses was repeatedly introduced from migratory aquatic birds to domestic ducks at sentinel farms on Poyang Lake during the past decade, and was detected in ducks at live-poultry markets in Nanchang [42]. However, neither the H10 nor N8 subtypes of avian influenza viruses had been detected in chickens before August 2013, despite the constant interaction of ducks with chickens [42]. Emergence of the H10N8 virus in chickens was accompanied with the incorporation of the H9N2 internal genes [40-43]. An outbreak of the newly reassorted H10N8 viruses in chickens was observed at the local markets, prior to the appearance of the human infections $[42,43]$. Subsequently the H10N8 virus reassorted with H5N6 viruses prevailing in multiple types of poultry in southern China to generate H10N6 viruses in chickens [42].

The emergence of the H10N8 and H10N6 viruses in Jiangxi province mirrors the scenario observed in the H7N9 outbreak and the generation of H7N7 and H7N6 viruses in eastern China. However, due to market closures, no H10N8, H10N6, H7N7 and H7N6 viruses have been detected since mid-2014. Only H7N9 viruses have persisted in the field.

\section{Factors of influenza ecology in China that favourite the virus emergence}

China is home to the world's largest human population. It also hosts the largest numbers of domestic ducks, geese, chickens, minor poultry and pigs. Frequent interactions among all these species and with wild life provide an ideal interface 
for transmission of viruses and the introduction of new viral gene components to the hosts.

With rapid economic growth and increasing wealth, farming and trading practices in China have been greatly changed by industrialization and globalization, in the quest for greater production and better quality food sources. Long-distance transportation of poultry and livestock to congregation sites, such as large wholesale markets or distribution centers, allows mixture and exchange of genetic material from viruses of different sources to generate novel variants and permits infectious agents to proliferate in larger, more diverse populations. Redistribution of asymptomatically infected live birds to retail markets, which are found in almost all cities and towns in China, allows a virus to be disseminated on a nationwide scale in weeks or months, leading to extensive human exposure.

As the H9N2, H5 and H6 subtypes of avian influenza viruses have become enzootic in the poultry of China since the mid-1990s [44-47], contribution of well-adapted genes from these viruses may lead to the genesis of novel viruses with increased infectivity and transmissibility in poultry, prossibly in humans as well.

A model of the genesis and interspecies transmission of novel influenza viruses in China's ecosystem (Fig. 4) shows that viruses from the wild aquatic birds, the natural reservoir for influenza A virus, can be occasionally introduced into the poultry production system by their sharing water bodies and habitats with domestic ducks (interface 1). Close interactions between ducks and chickens, either at the farms or live poultry markets (interface 2), allows viruses to enter terrestrial poultry, which can facilitate reassortment with enzootic chicken viruses to generate novel variants that may have the potential to infect humans. Extensive human exposure to such variants at live poultry markets (interface 3) can lead to sporadic human infections or even disease outbreaks as happened with the H7N9 
virus. Measures interrupting the live poultry supply chain or the virus transmission chain, especially those that act on the three interfaces, can help to control or prevent the emergence and dissemination of viruses.

\section{Conclusion}

H7N9 viruses have been persistent in poultry in China which shown a greater transmissibility to humans and other mammalian models than the Asian highly pathogenic H5Nx viruses [48-51], elevating concerns about their pandemic potential. To control H7N9 and other emerging avian influenza viruses, it is necessary to reconsider the management of the agricultural and trading practices currently in place in China. Measures such as, segregation of poultry species during breeding, transportation and trading; implementation of better biosecurity and hygienic controls throughout the entire poultry supply chain; the permanent closure of live poultry retail markets and the implementation of central slaughtering, will help to reduce the risk of novel viruses emerging, disease outbreaks and human exposure to pathogens. Systematic influenza surveillance remains essential for early warning of novel reassortant viruses and interspecies transmission events.

\section{Acknowledgements}

This study was supported by the National Institute of Allergy and Infectious Diseases (contract HHSN272201400006C), the Health and Medical Research Fund of the Hong Kong Government (RRG-10 and RRG-14), the Hong Kong Research Grant Council General Research Fund (RGC-GRF 17118515 and 17127714), the University Grants Committee of the Hong Kong SAR (AoE/M-12/06), the Shenzhen Peacock Plan High-End Talents Program (KQTD201203), the Guangdong Top-tier University Development Scheme and the Li Ka Shing Foundation. 


\section{Reference:}

1. Fouchier RAM, Guan Y: Ecology and evolution of influenza viruses in wild and domestic birds. In Textbook of Influenza, edn 2nd. Edited by Webster RG, Monto AS, Braciale TJ, Lamb RA: John Wiley \& Sons, Ltd.; 2013:173-189.

2. Claas EC, Osterhaus AD, van Beek R, De Jong JC, Rimmelzwaan GF, Senne DA, Krauss S, Shortridge KF, Webster RG: Human influenza A H5N1 virus related to a highly pathogenic avian influenza virus. Lancet 1998, 351:472-477.

* 3. Gao R, Cao B, Hu Y, Feng Z, Wang D, Hu W, Chen J, Jie Z, Qiu H, Xu K, et al.: Human infection with a novel avian-origin influenza A (H7N9) virus. $N$ Engl J Med 2013, 368:1888-1897.

This is the first report of the emergence of H7N9 influenza viruses in humans.

* 4. Li Q, Zhou L, Zhou M, Chen Z, Li F, Wu H, Xiang N, Chen E, Tang F, Wang D, et al.: Epidemiology of human infections with avian influenza $A(H 7 N 9)$ virus in China. N Engl J Med 2014, 370:520-532.

A study of the epidemiology of human H7N9 infections during the first outbreak wave.

5. Sun J, Gong Z, Lv H, Chen Z, Chai C, Liu S, Ling F, Lu Y, Cai J, Yu Z, et al.: Comparison of Characteristics between Patients with H7N9 Living in Rural and Urban Areas of Zhejiang Province, China: A Preliminary Report. PLoS One 2014, 9:e93775.

6. Tan KX, Jacob SA, Chan KG, Lee LH: An overview of the characteristics of the novel avian influenza A H7N9 virus in humans. Front Microbiol 2015, 6:140.

7. Yu H, Wu JT, Cowling BJ, Liao Q, Fang VJ, Zhou S, Wu P, Zhou H, Lau EH, Guo D, et al.: Effect of closure of live poultry markets on poultry-to-person 
transmission of avian influenza A H7N9 virus: an ecological study. Lancet 2014, 383:541-548.

8. To KK, Chan JF, Yuen KY: Viral lung infections: Epidemiology, virology, clinical features, and management of avian influenza A(H7N9). Curr Opin Pulm Med 2014, 20:225-232.

9. Wang XY, Chai CL, Li FD, He F, Yu Z, Wang XX, Shang XP, Liu SL, Lin JF: Epidemiology of human infections with avian influenza A(H7N9) virus in the two waves before and after October 2013 in Zhejiang province, China. Epidemiol Infect 2015, 143:1839-1845.

* 10. He F, Chen EF, Li FD, Wang XY, Wang XX, Lin JF: Human infection and environmental contamination with Avian Influenza A (H7N9) Virus in Zhejiang Province, China: risk trend across the three waves of infection. BMC Public Health 2015, 15:931.

This study provides comparative epidemiological data across the three H7N9 outbreak waves in Zhejiang, one of the most affected regions in China.

11. Chen E, Chen Y, Fu L, Chen Z, Gong Z, Mao H, Wang D, Ni MY, Wu P, Yu Z, et al.: Human infection with avian influenza $A(H 7 N 9)$ virus re-emerges in China in winter 2013. Euro Surveill 2013, 18.

12. Tu C, Fu L, Tang R, He T, Chen J, Fang Y, Wang J, Huang Z: The first case of avian influenza A (H7N9) virus occurring in the autumn season, China. Am J Infect Control 2014, 42:212-213.

** 13. Lam TT, Zhou B, Wang J, Chai Y, Shen Y, Chen X, Ma C, Hong W, Chen Y, Zhang Y, et al.: Dissemination, divergence and establishment of H7N9 influenza viruses in China. Nature 2015, 522:102-105.

Using systematic surveillance and large-scale whole genomic sequencing, the authors provide the most comprehensive dataset and evolutionary analyses on the H7N9 viruses during the first two waves, revealing the establishment of 
three geographically distinct virus lineages with at least 48 genotypes.

Chickens at live poultry markets were shown to be the major source of human infections.

* 14. Lu J, Wu J, Zeng X, Guan D, Zou L, Yi L, Liang L, Ni H, Kang M, Zhang X, et al.: Continuing reassortment leads to the genetic diversity of influenza virus H7N9 in Guangdong, China. J Virol 2014, 88:8297-8306.

The authors report the first H7N9 viruses introduced to Guangdong province during the wave 1 outbreak.

15. Chen Z, Li K, Luo L, Lu E, Yuan J, Liu H, Lu J, Di B, Xiao X, Yang Z:

Detection of avian influenza $A($ H7N9) virus from live poultry markets in Guangzhou, China: a surveillance report. PLoS One 2014, 9:e107266.

16. Ke C, Lu J, Wu J, Guan D, Zou L, Song T, Yi L, Zeng X, Liang L, Ni H, et al.: Circulation of reassortant influenza $A(H 7 N 9)$ viruses in poultry and humans, Guangdong Province, China, 2013. Emerg Infect Dis 2014, 20:2034-2040.

* 17. Yang Y, Zhang Y, Fang L, Halloran ME, Ma M, Liang S, Kenah E, Britton T, Chen E, Hu J, et al.: Household transmissibility of avian influenza A (H7N9) virus, China, February to May 2013 and October 2013 to March 2014. Euro Surveill 2015, 20:21056.

A systematic analysis of the human-to-human transmissibility of H7N9 viruses.

18. Qi X, Qian YH, Bao CJ, Guo XL, Cui LB, Tang FY, Ji H, Huang Y, Cai PQ, Lu B, et al.: Probable person to person transmission of novel avian influenza A (H7N9) virus in Eastern China, 2013: epidemiological investigation. BMJ 2013, 347:f4752.

19. Mao H, Guo B, Wang F, Sun Y, Lou X, Chen Y, Zhang L, Wang X, Li Z, Liu S, et al.: A study of family clustering in two young girls with novel avian 
influenza A (H7N9) in Dongyang, Zhejiang Province, in 2014. J Clin Virol 2015, 63:18-24.

20. Liu Y, Paquette SG, Zhang L, Leon AJ, Liu W, Xiuming W, Huang L, Wu S, Lin P, Chen W, et al.: The third wave: H7N9 endemic reassortant viruses and patient clusters. J Infect Dev Ctries 2015, 9:122-127.

21. Yi L, Guan D, Kang M, Wu J, Zeng X, Lu J, Rutherford S, Zou L, Liang L, Ni H, et al.: Family clusters of avian influenza A H7N9 virus infection in Guangdong Province, China. J Clin Microbiol 2015, 53:22-28.

22. Xiao XC, Li KB, Chen ZQ, Di B, Yang ZC, Yuan J, Luo HB, Ye SL, Liu H, Lu JY, et al.: Transmission of avian influenza $A($ H7N9) virus from father to child: a report of limited person-to-person transmission, Guangzhou, China, January 2014. Euro Surveill 2014, 19.

23. Chen Y, Liang W, Yang S, Wu N, Gao H, Sheng J, Yao H, Wo J, Fang Q, Cui D, et al.: Human infections with the emerging avian influenza A H7N9 virus from wet market poultry: clinical analysis and characterisation of viral genome. Lancet 2013

24. Wang X, Liu S, Mao H, Yu Z, Chen E, Chai C: Surveillance of Avian H7N9 Virus in Various Environments of Zhejiang Province, China before and after Live Poultry Markets Were Closed in 2013-2014. PLoS One 2015, 10:e0135718.

25. Han J, Jin M, Zhang P, Liu J, Wang L, Wen D, Wu X, Liu G, Zou Y, Lv X, et al.: Epidemiological link between exposure to poultry and all influenza A(H7N9) confirmed cases in Huzhou city, China, March to May 2013. Euro Surveill 2013, 18.

26. Yuan J, Lau EH, Li K, Leung YH, Yang Z, Xie C, Liu Y, Ma X, Liu J, Li X, et al.: Effect of Live Poultry Market Closure on Avian Influenza A(H7N9) Virus Activity in Guangzhou, China, 2014. Emerg Infect Dis 2015, 21:1784-1793. 
27. Chowell G, Simonsen L, Towers S, Miller MA, Viboud C: Transmission potential of influenza A/H7N9, February to May 2013, China. BMC Med 2013, 11:214.

28. Murhekar M, Arima Y, Horby P, Vandemaele KA, Vong S, Zijian F, Lee CK, Li A: Avian influenza A(H7N9) and the closure of live bird markets. Western Pac Surveill Response J 2013, 4:4-7.

* 29. Pantin-Jackwood MJ, Miller PJ, Spackman E, Swayne DE, Susta L, Costa-Hurtado M, Suarez DL: Role of poultry in the spread of novel H7N9 influenza virus in China. J Virol 2014, 88:5381-5390.

This study compared the infectivity and transmissibility of the H7N9 virus in different types of domestic birds and provides evidence of the asymptomatic infections caused by H7N9 viruses in poultry.

30. Kalthoff D, Bogs J, Grund C, Tauscher K, Teifke JP, Starick E, Harder T, Beer M: Avian influenza H7N9/13 and H7N7/13: a comparative virulence study in chickens, pigeons, and ferrets. J Virol 2014, 88:9153-9165.

31. Zaraket H, Baranovich T, Kaplan BS, Carter R, Song MS, Paulson JC, Rehg JE, Bahl J, Crumpton JC, Seiler J, et al.: Mammalian adaptation of influenza A(H7N9) virus is limited by a narrow genetic bottleneck. Nat Commun 2015, 6:6553.

32. Liu D, Shi W, Shi Y, Wang D, Xiao H, Li W, Bi Y, Wu Y, Li X, Yan J, et al.: Origin and diversity of novel avian influenza A H7N9 viruses causing human infection: phylogenetic, structural, and coalescent analyses. Lancet 2013, 381:1926-1932.

* 33. Wu A, Su C, Wang D, Peng Y, Liu M, Hua S, Li T, Gao GF, Tang H, Chen J, et al.: Sequential Reassortments Underlie Diverse Influenza H7N9 Genotypes in China. Cell Host Microbe 2013. 
The authors proposed a "sequential reassortment" model for the genesis of the H7N9 virus and discuss the genotypic diversity.

** 34. Lam TT, Wang J, Shen Y, Zhou B, Duan L, Cheung CL, Ma C, Lycett SJ, Leung CY, Chen X, et al.: The genesis and source of the H7N9 influenza viruses causing human infections in China. Nature 2013, 502:241-244.

Using a combination of active surveillance, screening of virus archives, and evolutionary analyses, the authors revealed the genesis and source of the H7N9 virus. An H7N7 virus closely related to the H7N9 virus was also detected in Zhejiang province.

*35. Cui L, Liu D, Shi W, Pan J, Qi X, Li X, Guo X, Zhou M, Li W, Li J, et al.: Dynamic reassortments and genetic heterogeneity of the human-infecting influenza A (H7N9) virus. Nat Commun 2014, 5:3142.

The authors analyzed the genetic heterogeneity of the wave $1 \mathrm{H} 7 \mathrm{~N} 9$ viruses and proposed a "dynamic reassortment" model for the genesis and evolution of this virus.

36. Wang D, Yang L, Gao R, Zhang X, Tan Y, Wu A, Zhu W, Zhou J, Zou S, Li X, et al.: Genetic tuning of the novel avian influenza $A(H 7 N 9)$ virus during interspecies transmission, China, 2013. Euro Surveill 2014, 19.

37. Zhou X, Li Y, Wang Y, Edwards J, Guo F, Clements AC, Huang B, Soares Magalhaes RJ: The role of live poultry movement and live bird market biosecurity in the epidemiology of influenza A (H7N9): A cross-sectional observational study in four eastern China provinces. J Infect 2015, 71:470-479.

38. Liu W, Yang K, Qi X, Xu K, Ji H, Ai J, Ge A, Wu Y, Li Y, Dai Q, et al.: Spatial and temporal analysis of human infection with avian influenza A(H7N9) virus in China, 2013. Euro Surveill 2013, 18. 
* 39. Chen H, Yuan H, Gao R, Zhang J, Wang D, Xiong Y, Fan G, Yang F, Li X, Zhou J, et al.: Clinical and epidemiological characteristics of a fatal case of avian influenza A H10N8 virus infection: a descriptive study. Lancet 2014, 383:714-721.

This is the first report on the emergence of an H10N8 influenza virus in humans.

40. Liu M, Li X, Yuan H, Zhou J, Wu J, Bo H, Xia W, Xiong Y, Yang L, Gao R, et al.: Genetic diversity of avian influenza A (H10N8) virus in live poultry markets and its association with human infections in China. Sci Rep 2015, 5:7632.

41. Qi W, Zhou X, Shi W, Huang L, Xia W, Liu D, Li H, Chen S, Lei F, Cao L, et al.: Genesis of the novel human-infecting influenza $\mathrm{A}(\mathrm{H10N8})$ virus and potential genetic diversity of the virus in poultry, China. Euro Surveill 2014, 19.

** 42. Ma C, Lam TT, Chai Y, Wang J, Fan X, Hong W, Zhang Y, Li L, Liu Y, Smith DK, et al.: Emergence and evolution of H10 subtype influenza viruses in poultry in China. J Virol 2015, 89:3534-3541.

This study conducts a longitudinal survey and shows the prevalence, interspecies transmission and evolution of H10 subtype influenza viruses in China. It also reveals the genesis and development of the H10N8 virus that caused human infections in 2013-2014.

43. Xu Y, Cao H, Liu H, Sun H, Martin B, Zhao Y, Wang Q, Deng G, Xue J, Zong Y, et al.: Identification of the source of A (H10N8) virus causing human infection. Infect Genet Evol 2015, 30:159-163.

44. Xu KM, Smith GJ, Bahl J, Duan L, Tai H, Vijaykrishna D, Wang J, Zhang JX, Li KS, Fan XH, et al.: The genesis and evolution of H9N2 influenza viruses in poultry from southern China, 2000 to 2005. J Virol 2007, 81:10389-10401. 
45. Chen H, Smith GJ, Li KS, Wang J, Fan XH, Rayner JM, Vijaykrishna D, Zhang JX, Zhang LJ, Guo CT, et al.: Establishment of multiple sublineages of H5N1 influenza virus in Asia: implications for pandemic control. Proc Natl Acad Sci U S A 2006, 103:2845-2850.

46. Cheung CL, Vijaykrishna D, Smith GJ, Fan XH, Zhang JX, Bahl J, Duan L, Huang K, Tai H, Wang J, et al.: Establishment of influenza A virus (H6N1) in minor poultry species in southern China. J Virol 2007, 81:10402-10412.

47. Huang K, Zhu H, Fan X, Wang J, Cheung CL, Duan L, Hong W, Liu Y, Li L, Smith DK, et al.: Establishment and lineage replacement of $\mathrm{H6}$ influenza viruses in domestic ducks in southern China. $J$ Virol 2012, 86:6075-6083.

48. Zhu H, Wang D, Kelvin DJ, Li L, Zheng Z, Yoon SW, Wong SS, Farooqui A, Wang J, Banner D, et al.: Infectivity, transmission, and pathology of human-isolated H7N9 influenza virus in ferrets and pigs. Science 2013, 341:183-186.

49. Xu L, Bao L, Deng W, Dong L, Zhu H, Chen T, Lv Q, Li F, Yuan J, Xiang Z, et al.: Novel avian-origin human influenza $A($ H7N9) can be transmitted between ferrets via respiratory droplets. J Infect Dis 2014, 209:551-556.

50. Yen HL, Lipatov AS, Ilyushina NA, Govorkova EA, Franks J, Yilmaz N, Douglas A, Hay A, Krauss S, Rehg JE, et al.: Inefficient transmission of H5N1 influenza viruses in a ferret contact model. $J$ Virol 2007, 81:6890-6898.

51. Pulit-Penaloza JA, Sun X, Creager HM, Zeng H, Belser JA, Maines TR, Tumpey TM: Pathogenesis and Transmission of Novel Highly Pathogenic Avian Influenza H5N2 and H5N8 Viruses in Ferrets and Mice. J Virol 2015, 89:10286-10293. 


\section{Figure Captions}

Figure 1. Distribution of officially reported H7N9 infection cases in humans since

February 2013. (A) Geographic distribution of the H7N9 influenza viruses in China. Provinces in China with confirmed human H7N9 cases are in blue, those without human cases but positive for H7N9 in poultry or the environment are in light blue, while those without any evidence of H7N9 infections are in grey. (B) Number of humans confirmed to be infected with H7N9 during the first (yellow), second (red) and third (green) waves. Data (as of September 2015) are available at the Food and Agriculture Organization of the United Nations website (URL:

http://www.fao.org/ag/againfo/programmes/en/empres/H7N9/wave_3/Situation_updat e_2015_09_29.html).

\section{Figure 2. Epidemiology and evolution of H7N9 influenza virus. (A) HA} phylogenetic tree of the H7N9 lineage. H7N9 viruses from the first, second and third outbreak waves have background colors of yellow, red and green, respectively. Clades $\mathrm{A}, \mathrm{B}$ and $\mathrm{C}$, identified during the second wave are indicated with red branches on the tree. Human isolates are indicated by blue ovals at node tips. SH1 and SH5 indicate the Shanghai/1/2013 and Shanghai/05/2013 viruses, which are closest to the root of the lineage. The scale bar to the left of the tree represents a branch length of 0.002 substitutions/site. (B) Number of human cases of H7N9 infection (data last updated on September 29, 2015, Food and Agriculture Organization of the United Nations website; URL: http://www.fao.org/ag/againfo/programmes/en/empres/H7N9/wave_3/Situation_updat e_2015_09_29.html). Major intervals are years; minor intervals are weeks.

Figure 3. Phylogenies illustrating the emergence of H7N9 and H10N8 influenza viruses. Phylogenies of (A) H7 and (B) H10 hemagglutinin genes and (C) PB2 polymerase gene were constructed by the maximum likelihood (ML) method in PhyML v3. The names of human and domestic duck viruses are displayed in red and 
purple. Lineages of H7N9, H7N7 and H10N8 viruses in (A) and (B) are indicated by red branches. Transmissions of viruses from domestic ducks to chickens are illustrated by red arrows. The PB2 phylogeny $(\mathbf{C})$ shows the recent H9N2 influenza lineage in China. The tree is compressed for visual clarity, with H7N9, H7N7, H10N8 and H5Nx viruses indicated by colored circles as defined in the legend. Branch length scale bars given under the trees are 0.01 substitutions/site.

Figure 4. The current ecosystem of avian influenza viruses in China. Arrowheads indicate the directions of transmissions. 
(B) Canada $\| 2 \quad$ Wave 3 (Oct 2014-Sep 2015)

$$
\begin{aligned}
& \begin{array}{l|l}
\text { Malaysia } & 1 \\
& \text { Wave } 2 \text { (Oct 2013-Sep 2014) }
\end{array} \\
& \text { Hubei } \mid 1
\end{aligned}
$$

Guizhou 11

Hebei 1

Jilin $\mid 2$

Guangxi 3

Taiwan 13

Henan 4

Shandong 232

Beijing 331

Jiangxi 623

Xinjiang 37

Hong Kong 103

Anhui 41414

Hunan 2202

Fujian $517 \quad 41$

with H7N9 human cases with $\mathrm{H} 7 \mathrm{~N} 9$ in birds without reported cases

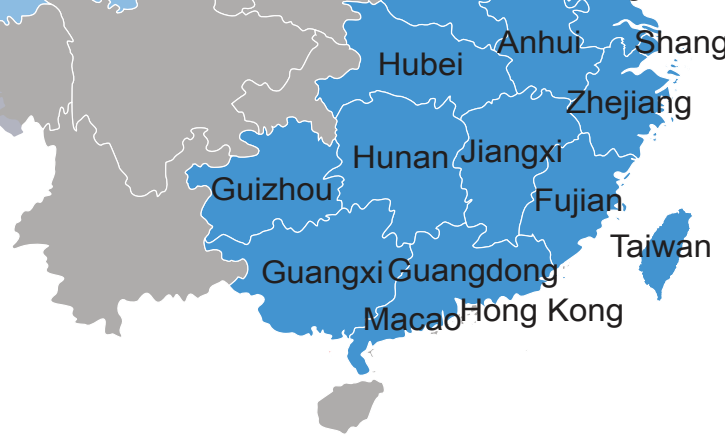

Shanghai $\quad 33 \quad 86$

\begin{tabular}{l|l|l|l} 
Jiangxi & 27 & 28 & 22
\end{tabular}

Guangdong 110

\begin{tabular}{rrrrrrr} 
Zhejiang & \multicolumn{2}{c}{46} & \multicolumn{2}{c}{93} & \multicolumn{2}{c}{46} \\
\cline { 2 - 6 } & \multicolumn{2}{c}{46} & 1 & 1 & \\
& & 50 & 100 & 150 & 200
\end{tabular}

Figure 1. 
(A) $\mathrm{H} 7$ hemagglutinin gene

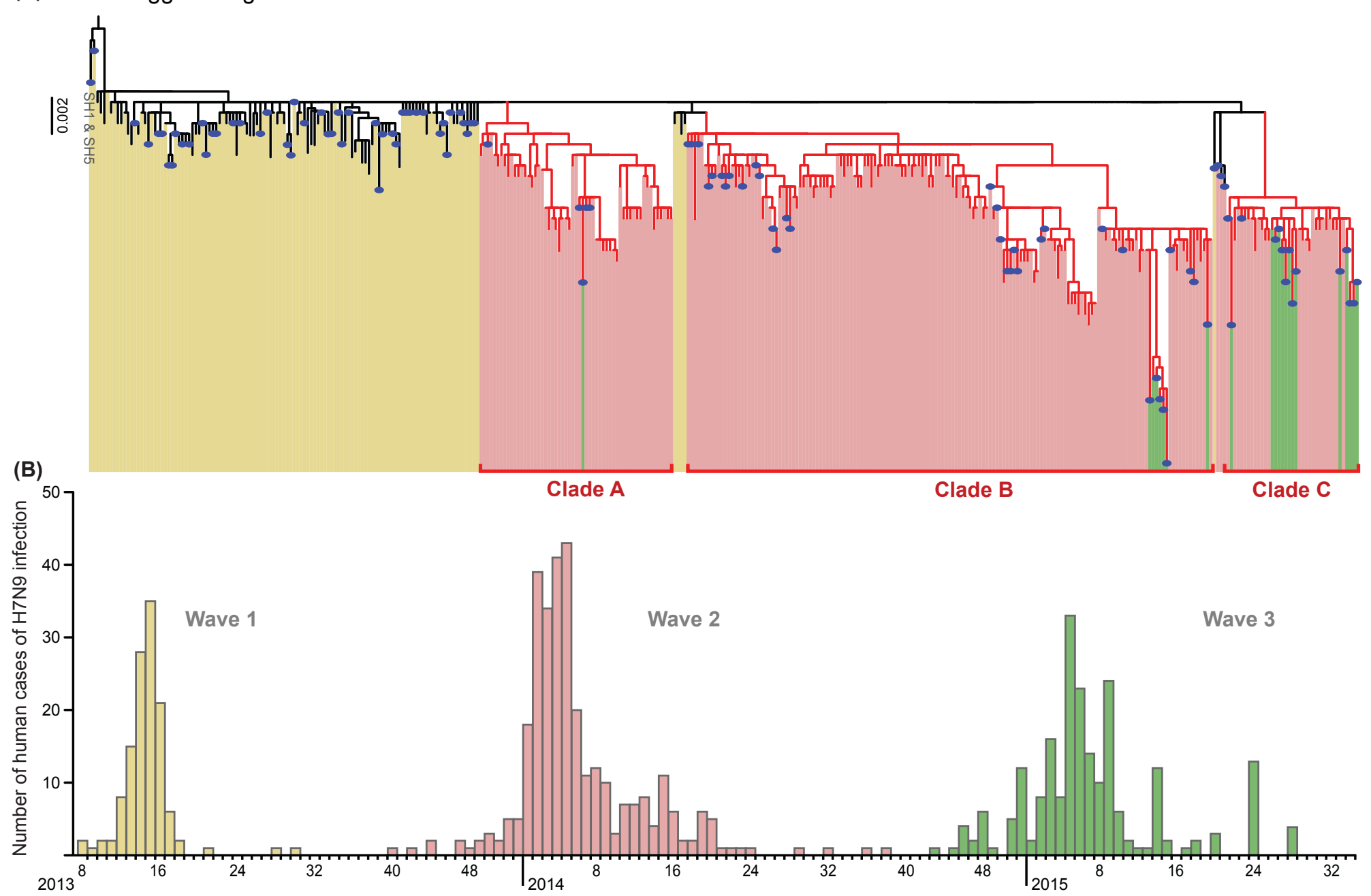

Figure 2. 
(A) H7 hemagglutinin gene

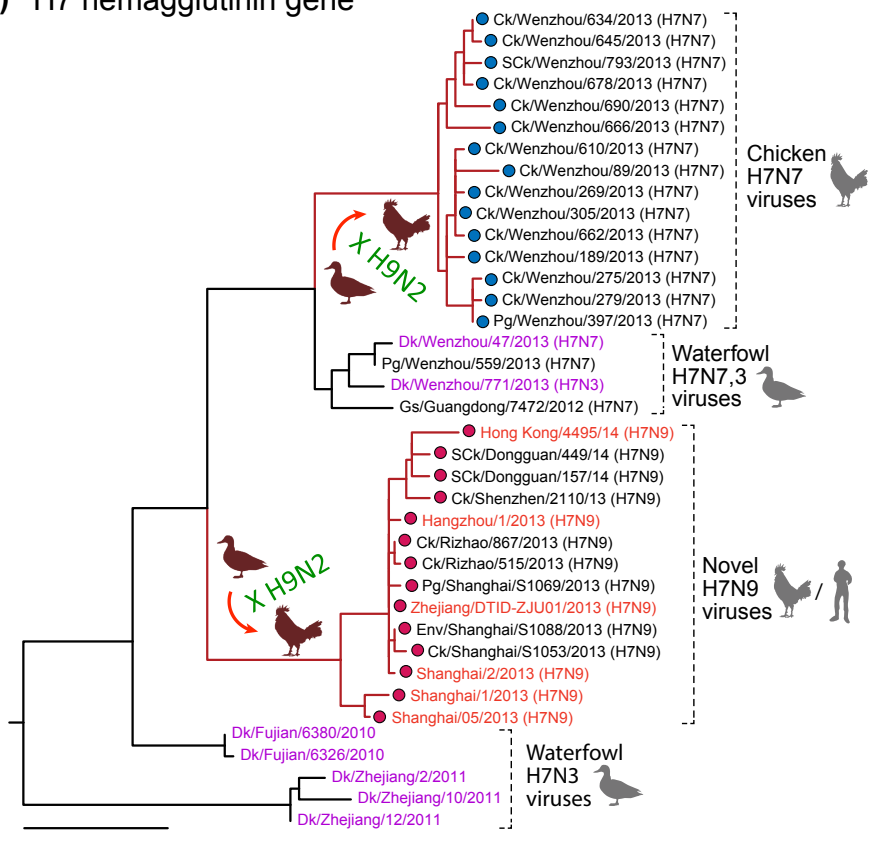

(B) H10 hemagglutinin gene

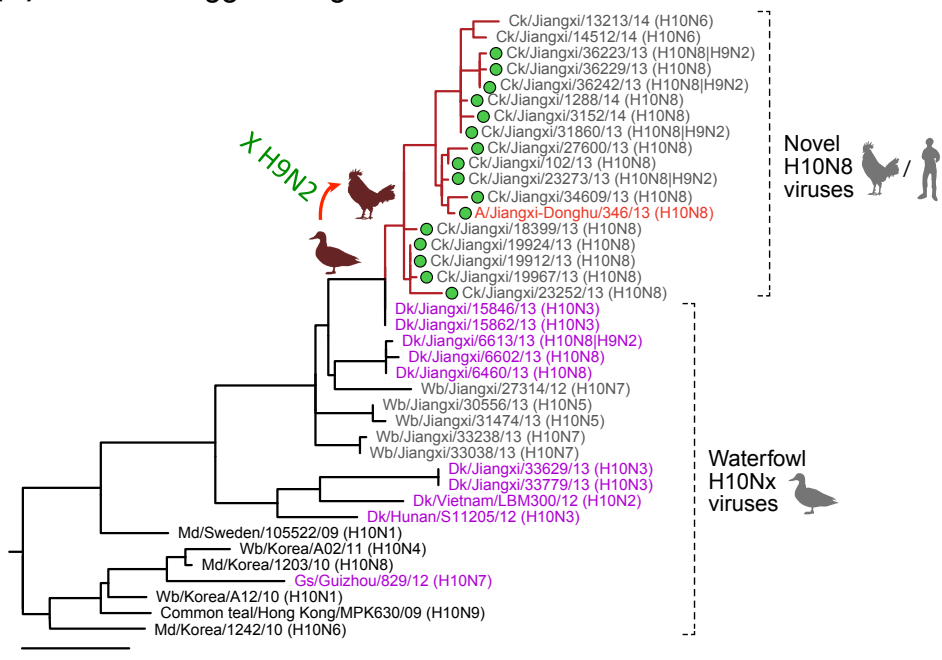

(C) PB2 polymerase gene
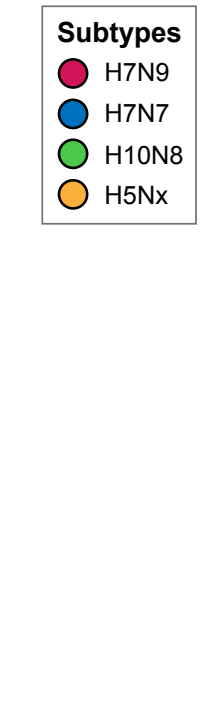

Figure 3. 


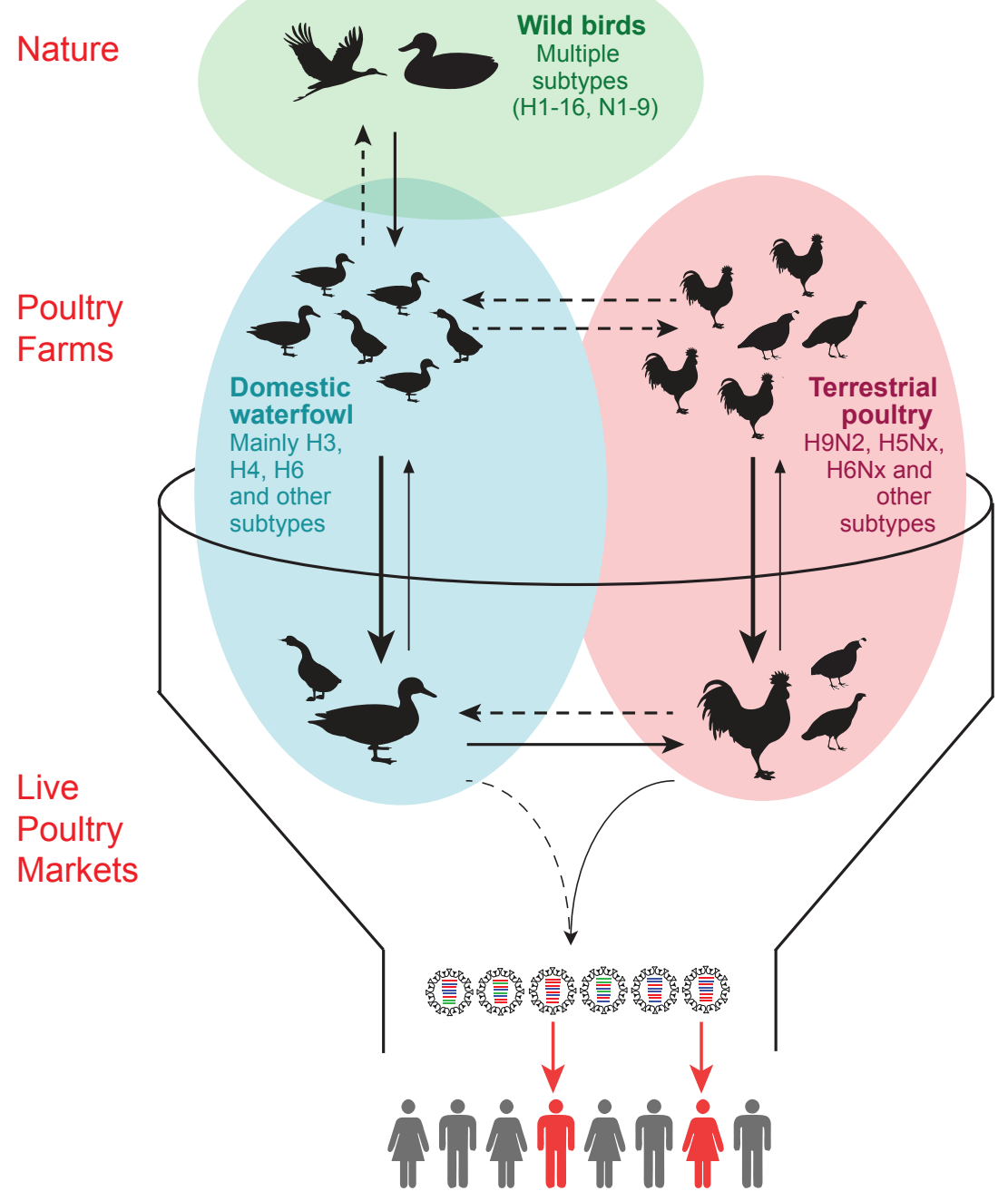

Figure 4. 